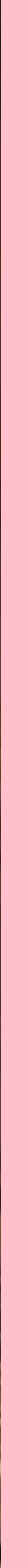




\title{
Processos sociais de apropriação de espaços públicos urbanos para o lazer: uma interpretação sobre os fundamentos legais da ocupação do Minhocão, em São Paulo
}

Social processes of public urban spaces appropriation for leisure: an interpretation of legal fundamentals of Minhocão occupation, in São Paulo

Laís Barreto de Amorim ${ }^{1}$

Ana Paula Garcia Spolon ${ }^{2}$

\begin{abstract}
1 Formação Técnica em Marketing pelo Centro Paulo Souza, Etec Carlos de Campos (2011) e Cursando Tecnologia em Gestão de Turismo(2013) pelo Instituto Federal de Educação, Ciência e Tecnologia de São Paulo. Atualmente trabalha como estagiaria no Grupo Cantatur.. Email: laisbamorim@hotmail.com
\end{abstract}

2Pós-doutorado em Ciências (Hospitalidade), pela Escola de Artes, Ciências e Humanidades da Universidade de São Paulo (EACH-USP). Pós-doutorado em Geografia - Análise Territorial e Estudos Turísticos, pela Universitat Rovira i Virgili (Tarragona, Espanha), com vínculo adicional com o Departamento de Geografia Humana da Universidad de Barcelona (Espanha). Doutora e mestre em Arquitetura e Urbanismo pela Faculdade de Arquitetura e Urbanismo da Universidade de São Paulo (FAU-USP). Especialista em Administração de Empresas pela Fundação Getúlio Vargas (FGV-SP). Graduada em Letras (UNESP) e em Hotelaria (SENAC-SP). Professora Adjunta da Faculdade de Turismo e Hotelaria da Universidade Federal Fluminense (FTH-UFF), em Niterói/RJ. Líder do grupo de pesquisa \&quot;HoSt - Rede de Estudos em Hospitalidade\&quot; (CNPq/UFF). Membro dos grupos de pesquisa \&quot;Turismo: Gestão e Territórios\&quot; (CNPq/UFF) e \&quot;Turismo: Desenvolvimento Humano e Social, Linguagem e Processos Educacionais\&quot; (CNPq/UCS). Fundadora da HoSt - Hospitality Studies Network. Revisora, redatora e tradutora (português, inglês e espanhol), em especial para publicações das áreas de turismo, hospitalidade e estudos urbanos. Temas de pesquisa: (a) HOSPITALIDADE - estudos e pesquisas teóricas e aplicadas em hospitalidade; hospitalidade em contextos contemporâneos; turismo, hospitalidade e cosmopolitismo, (b) ESTUDOS URBANOS - turismo, hospitalidade e os processos de produção e consumo dos espaços urbanos contemporâneos e (c) PLANEJAMENTO E GESTÃO EM HOSPITALIDADE - planejamento, desenvolvimento e gestão estratégica de produtos e serviços de hotelaria, gastronomia, eventos e lazer.. E-mail: anapaulaspolon@gmail.com 


\section{RESUMO}

O presente artigo fala sobre processos sociais de apropriação de espaços públicos urbanos para novos usos. Para tanto, analisa o conjunto de instrumentos legais que fundamentam a ocupação parcial e gradual do Minhocão para uso como espaço de lazer, investigando ainda a opinião dos usuários sobre este processo. Foram realizadas pesquisas bibliográfica e de campo, ambos de caráter qualitativo e analítico, suportadas por fundamentos conceituais sobre os temas de espaços urbanos, parques urbanos e direito à cidade. Os resultados reforçam a hipótese de que o aparato legal favorece o processo, à medida que garante a efetivação de direitos democráticos, promove a ocupação diversificada do território e fortalece a função social da cidade. Destaca-se a importância deste estudo, para o entendimento do lazer na cidade e do turismo na formação do espaço, como símbolo da promoção de novas experiências.

Palavras-chave: Espaços Públicos Urbanos. Lazer urbano. Políticas Públicas. Minhocão. São Paulo.

\section{ABSTRACT}

This article speaks about social processes of public spaces appropriation for new usages. To this end, it analyses the set of legal instruments that underpin partial and gradual occupation of Minhocão for use as space of leisure, thus investigating users' opinion on this process. Bibliographical and field research have been carried out, both of qualitative and analytical nature, supported by conceptual foundations on the themes of urban spaces, urban parks and right to the city. The results reinforce the hypothesis that the legal apparatus favors the process, since it ensures the enforcement of democratic rights, promotes diversified occupation of territory and strengthens city's social function. It is important to note the importance of this study to the understanding of leisure in the city and tourism in formation of space as symbol of new experiences' promotion.

Keywords: Urban Public Spaces. Urban Leisure. Public policies. Minhocão. São Paulo.

Introdução

"[...] a bela cidade constitui o equipamento mais apropriado para que o lazer possa se desenvolver".

(Nelson Carvalho Marcelino)

O presente estudo fala sobre lazer e planejamento urbano e tem por tema os processos de apropriação de espaços públicos urbanos para novos usos. Visa compreender, a partir da apresentação e da interpretação de um conjunto de instrumentos legais, a disposição jurídica que regulamenta a adoção de políticas públicas que orientam os processos de apropriação de espaços urbanos. Para interpretação desses processos de apropriação e de instalação de estruturas de lazer, mais especificamente dos parques urbanos, o artigo concentra-se no objetivo de análise da forma de aplicação desses instrumentos legais, de mecanismos democráticos e de práticas sociais que deram suporte para o projeto de lei que passou a denominar "Parque Minhocão" o antigo Elevado Presidente Costa e Silva, considerando-o espaço e equipamento público de lazer destinado a moradores e visitantes, no centro de São Paulo, em tempo parcial.

Para tanto, optou-se por trabalhar com os fundamentos conceituais sobre espaços urbanos (MARCELINO, 1995) e parques urbanos (SANTINI, 1993), analisados pelas vertentes (a) dos processos sociais de produção de espaço urbano e do direito à cidade, conforme preconizados por Lefebvre $(2006,2008)$ e (b) dos processos de elaboração de políticas públicas para acesso a espaços e equipamentos de lazer em áreas urbanas, como apresentados por Marcelino (1995, 2001, 2002).

A pesquisa faz uso de dados secundários colhidos através de consultas em livros e artigos e também de análise documental direta e aplicação de questionário. Apoia-se ainda em análise in loco da infraestrutura do parque e em entrevistas qualitativas para identificação do nível de satisfação dos usuários em relação à maneira atual de uso do espaço. Registre-se, portanto, a prática de proibição do tráfego de veículos na região, os diferentes níveis de apropriação do espaço e a intensidade de 
CENÁRIO, Brasília, V.5, n.9 | 128-139 | Dez. 2017 | p. 128

uso deste equipamento, nos últimos meses. Observações permitiram identificar perdas e ganhos, não só para os visitantes, mas também para moradores.

A seguir, apresenta-se as considerações sobre a fundamentação teórica e o tema. Delimita-se ainda o estudo de caso, destacando-se as características específicas e o contexto histórico de implantação do Minhocão. Discute-se na sequência o conjunto de instrumentos legais que vieram a permitir o novo uso do espaço. Procede-se à apresentação e discussão dos resultados das entrevistas e à conclusão do artigo.

O estudo parte da hipótese de que a ocupação do espaço do Minhocão pela população paulistana e por visitantes da cidade, bem como sua apropriação como equipamento de lazer foi possível graças (a) a um conjunto de instrumentos legais que guardam entre si elevado grau de conexão, (b) à participação efetiva da população no processo de ocupação e apropriação da área como espaço de lazer e turismo.

No texto, são feitas considerações acerca da importância dos espaços urbanos de lazer para construção de uma imagem mais positiva da cidade e para o papel dos usuários no processo que pode oportunizar a promoção de novos ambientes de encontro e interação, o que maximiza o potencial turístico da região. O fundamento teórico desta discussão considera a cidade como um tecido fragmentado que apresenta distintos níveis de apropriação de seus espaços. O destino escolhido para análise é a cidade São Paulo, capital do Estado de São Paulo, no Brasil. Pesquisa-se especificamente o chamado Parque Minhocão e a condição de sua apropriação como espaço de lazer, pela população local e por visitantes da cidade.

O antigo Elevado Presidente Costa e Silva, atual Parque Minhocão

O antigo Elevado Presidente Costa e Silva, o "Minhocão", em São Paulo, foi inaugurado no dia 25 de janeiro de 1971. Trata-se de uma via elevada de cerca de três quilômetros de extensão, com quatro pistas e com largura aproximada de quinze metros e altura máxima de cinco metros. Seu traçado está detalhado na Figura 1.

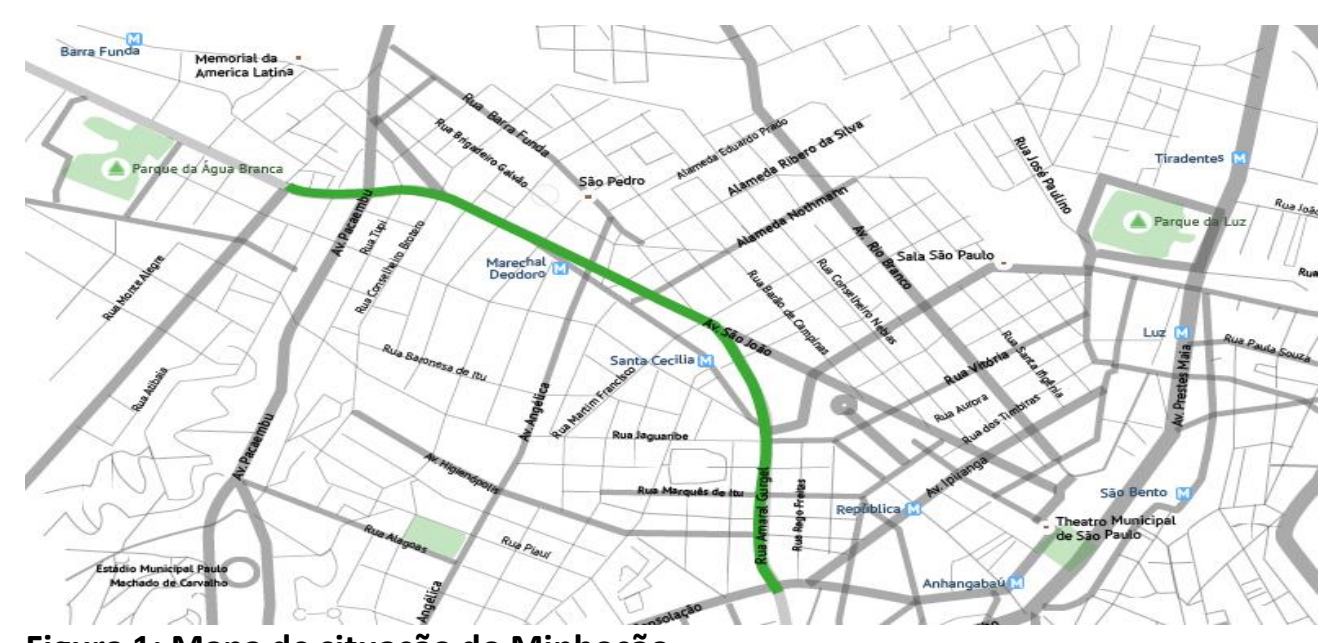

Figura 1: Mapa de situação do Minhocão

Fonte: Elaborado a partir de informações da Associação Parque Minhocão

Em certos pontos do trajeto, a distância mínima das janelas dos prédios até a via é de cinco metros. O elevado tem quatro pistas sob as vigas e atravessa três distritos da cidade. O traçado liga a Praça Roosevelt, no centro, ao Largo Padre Péricles, em Perdizes, passando pela Rua Amaral Gurgel, Av. São João, Praça Marechal Deodoro e Av. General Olímpio da Silveira.

O projeto para construção do elevado foi idealizado em 1968, com intuito de diminuir o trânsito local. Elaborado na gestão do prefeito José Vicente Faria Lima (1965-1969), o projeto foi recusado devido às reações negativas registradas à época, por parte dos próprios técnicos e também da 
CENÁRIO, Brasília, V.5, n.9 | 129-139 | Dez. 2017 | p. 129

população. Em 1970, na gestão do prefeito Paulo Salim Maluf (1969-1971), o projeto retornou para a Câmara Municipal e tornou-se uma obra concebida e executada. A inauguração ocorreu em 25 de janeiro de 1971, data de comemoração do aniversário da cidade de São Paulo, sendo a via apelidada de Minhocão, nome pelo qual é desde então conhecida. A via é até hoje apresentada como uma marca desta gestão de Paulo Maluf.

Pode-se afirmar que o Minhocão foi uma construção moderna para a época, porém causou impacto inegável, em decorrência de problemas, como acidentes rotineiros, poluição sonora, ambiental e visual, migração das atividades econômicas para outras áreas, falta de privacidade dos moradores locais e a decorrente desvalorização dos imóveis, do comércio e da área do seu entorno. Por conta desses impactos, em 1990 a então prefeita Luiza Erundina de Souza (1989-1992) determinou a proibição do trânsito no local aos domingos e feriados, restringindo o funcionamento da via durante a semana, fechando-a em grande parte da noite (das 21:00 às 6:30 horas).

Nesse contexto, o elevado passou a ser parcial e intuitivamente utilizado como um equipamento de lazer pelos moradores da região. Em 1996, o novamente prefeito Paulo Salim Maluf (1993-1996) pretendeu a reabertura do Minhocão, tendo sido impedido pela Câmara Municipal, que decretou e promulgou a Lei no 12.152, de 23 de julho de 1996, de autoria do então vereador José Eduardo Cardozo, que vetaria o tráfego de veículos na via nesses períodos, determinando seu uso para lazer. Nos anos subsequentes, foram muitas as propostas de demolição do elevado e de transformação do espaço por ele ocupado. No julgamento dessas várias propostas decorrentes do eventual processo de demolição, em 6 de maio de 2010, o prefeito Gilberto Kassab (2006-2012) divulgou um projeto visando a demolição do Minhocão, porém, a partir da gestão do atual prefeito Fernando Haddad (2013), em 31 de julho de 2014 foi votado o novo Plano Diretor Estratégico da Cidade de São Paulo (PDESP), a Lei (16.050/14), que está em vigência desde o momento de sua aprovação.

O PDESP determina a redução gradual da circulação de veículos no elevado, sendo prevista a sua completa desativação como via de tráfego, ou outras medidas, como a demolição ou a transformação de uso, criando-se a condição parcial ou integral de novo uso.

Em julho de 2015, a Companhia de Engenharia de Tráfego (CET) determinou a interrupção do tráfego para mais cedo, direcionando o fechamento do trânsito aos sábados, a partir das 15 horas e aos domingos o dia todo.

Desta forma, atualmente a via elevada é destinada a uso público por pedestres e proibida para carros entre as 15 horas de sábado e as 6:30 horas de segunda-feira, além de todas as noites durante a semana, entre as $21: 30$ horas e as 6:30 horas da manhã. Tem-se, portanto, 47,92\% do tempo semanal destinado a uso exclusivo por carros e $52,08 \%$ do tempo destinado a pedestres.

Recentemente, a via passou a chamar-se "Parque Minhocão", diante da aprovação do projeto de Lei no 439/2015, apresentado pelo vereador José Police Neto (PSD), pela Câmara Municipal e sancionado em março de 2016 pelo atual prefeito Fernando Haddad. Na prática, a medida não modifica a estrutura do elevado e nem as formas de uso do Minhocão pelo público, continuando permitida a apropriação do espaço como anteriormente descrito. Com a nomenclatura, entretanto, dá-se força para a adoção de medidas que, até 2030 , devem levar à desativação completa da via elevada.

Ainda com referência à legalização do Minhocão, registre-se que foi protocolado na Câmara Municipal de São Paulo o Projeto de Lei no 143/2016, do vereador Jamil Murad do PCdoB, que "altera denominação do Elevado Presidente Arthur da Costa e Silva para Minhocão e dá outras providências" (SÃO PAULO, 2016).

Este projeto apoia-se ainda na proposta de alteração de nome de logradouros "quando se tratar de denominação referente à autoridade que tenha cometido crime de lesa-humanidade ou graves violações de direitos humanos" (SÃO PAULO, 2016), como previsto pela lei no 380/2010.

\section{Análise da legislação relativa ao processo de apropriação do Minhocão para uso como equipamento de lazer}

O processo social de apropriação do espaço do Minhocão como equipamento de lazer urbano segue, em São Paulo, determinações de política urbana dadas pelo conjunto de instrumentos que 
CENÁRIO, Brasília, V.5, n.9 | 130-139 | Dez. 2017 | p. 130 regulamentam o planejamento urbano, a ordenação territorial e a forma de desenvolvimento espacial da cidade, nos próximos anos. Os documentos analisados neste trabalho foram aqueles diretamente relacionados ao direito ao lazer e à cidade: (a) o Plano Diretor Estratégico do Município de São Paulo (PDESP), (b) a Lei de Parcelamento, Uso e Ocupação do Solo (LUOS), que inclui os Planos Regionais Estratégicos das Subprefeituras (Região Centro) e (c) o Projeto de Lei no 439/2015. O Plano Diretor abrange o conjunto de leis, estratégias e medidas para ordenação do crescimento da cidade, enquanto a Lei de Parcelamento, Uso e Ocupação do Solo (LUOS) pode ser definida como o conjunto de regras sobre o parcelamento (tamanho do lote), uso (atribuição da função do espaço) e ocupação (normas de implantação de edificações).

A análise iniciou no âmbito da política urbana do município de São Paulo, interpretando a Lei no 16.050 de 2014 (PREFEITURA..., 2014), a qual estabeleceu o novo Plano Diretor Estratégico do Município de São Paulo (PDESP), um dos instrumentos do planejamento municipal que integra o processo de planejamento da cidade, dispõe sobre a totalidade do território do município e normatiza a forma de uso e ocupação do solo na cidade, além de definir as estratégias de ordenamento ao interesse social, cultural e ambiental.

A Política de Desenvolvimento Urbano é o "conjunto de planos e ações que tem como objetivo ordenar o pleno desenvolvimento das funções sociais da cidade e o uso socialmente justo e ecologicamente equilibrado e diversificado de seu território, de forma a assegurar o bem-estar e a qualidade de vida de seus habitantes", como definido no Artigo 1ㅇ, parágrafo 1ㅇ (PREFEITURA..., 2014). O Plano Diretor Estratégico é, segundo descrito em seu Artigo 1으, parágrafo 3o, o "instrumento básico da Política de Desenvolvimento Urbano do Município de São Paulo, determinante para todos os agentes públicos e privados que atuam em seu território" (PREFEITURA..., 2014).

No capítulo II, que descreve os Princípios, Diretrizes e Objetivos, destacam-se no Artigo 5o os princípios orientadores que regem a Política de Desenvolvimento Urbano e o Plano Diretor Estratégico (SÃO PAULO, 2014, grifos nossos), quais sejam:

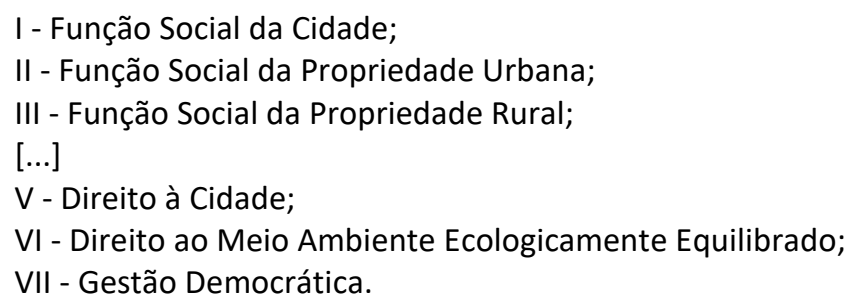

Os destaques apontados são apresentados na Lei 16.050/2014 da seguinte forma: define-se Função Social da cidade como as "necessidades dos cidadãos quanto à qualidade de vida, à justiça social, [...] ao sossego e ao lazer" (PREFEITURA..., 2014).

O Direito à Cidade, por sua vez, é definido como "o processo de universalização do acesso aos benefícios e às comodidades da vida urbana por parte de todos os cidadãos, seja pela oferta e uso dos serviços, equipamentos e infraestruturas públicas", sendo capaz de garantir "a cidadania cultural, a tolerância e o respeito à diversidade cultural, social, étnica e sexual por meio do acesso à cultura, à educação e à arte" (PREFEITURA..., 2014).

A Gestão Democrática é a "garantia da participação de representantes dos diferentes segmentos da população, diretamente ou por intermédio de associações representativas [...]". A própria definição dos mecanismos da gestão faz referência ao "pleno acesso público, garantindo a transparência, acesso à informação, a participação e os preceitos da gestão democrática” (PREFEITURA..., 2014). A construção das diretrizes do próprio Plano Diretor se fundamentou na defesa de uma cidade democrática, capaz de garantir a qualidade de vida e o acesso aos serviços. 
CENÁRIO, Brasília, V.5, n.9 | 131-139 | Dez. 2017 | p. 131 Os princípios do artigo 5 consistem na construção de conceitos nos quais prevalecem estratégias para o desenvolvimento de uma cidade democrática, tendo como intuito garantir a qualidade de vida, por meio de diretrizes e diplomas legais capazes de fazer cumprir estes compromissos perante a sociedade. Esses princípios são, neste trabalho, discutidos a partir do proposto teoricamente por Henri Lefebvre $(2006,2008)$ e Nelson Carvalho Marcelino (1995, 2001, 2002).

Para Lefebvre (2006, p. 46), a cidade sempre teve relações com a sociedade no seu conjunto, com sua composição e seu funcionamento, com seus elementos constituintes e com sua história, como um organismo que "[...] muda quando muda a sociedade no seu conjunto". Neste pensamento, identificamos a ligação entre a cidade e o indivíduo em sociedade, ligação sempre marcada pelo contexto histórico. $\mathrm{O}$ indivíduo que vive em sociedade produz os seus direitos de acordo com suas necessidades, buscando esses direitos em sua própria história e inserindo neste contexto a cidade com a qual deseja identificar-se. Assim, Lefebvre (2006, p. 47) considera que "[...] se há uma produção da cidade, e das relações sociais na cidade, é uma produção e reprodução de seres humanos por seres humanos, mais do que uma produção de objetos". Neste processo do exercício do direito à cidade, o autor complementa que:

Face a esse direito, ou pseudodireito, o direito à cidade se afirma como um apelo, como uma exigência. Através de surpreendentes desvios - a nostalgia, o turismo, o retorno para o coração da cidade tradicional, o apelo das centralidades existentes ou recentemente elaboradas - esse direito caminha lentamente (LEFEBVRE, 2006, p. 116).

Esta proposta de postura frente à conquista do espaço urbano pela sociedade permite compreender a ação de transformação do direito e os movimentos sociais de produção da cidade e de reprodução do espaço diante do movimento geral da sociedade. Na interpretação do autor, o direito à cidade deve ser "[...] formulado como direito à vida urbana, transformada, renovada" (LEFEBVRE, 2006, p. 117). A análise do direito à cidade promove o reconhecimento da produção espacial que se manifesta no cotidiano, quando a participação da atividade humana vai favorecendo e fortalecendo o processo de construção da própria identidade da cidade.

Neste breve recorte dos princípios orientadores do artigo 5ㅇ, reconhecemos o posicionamento de Lefebvre como a concepção que consideramos a mais adequada. Outras opiniões auxiliam na conceituação de termos e na construção de pensamentos sobre a relação entre o lazer e a apropriação de espaços públicos urbanos.

Marcelino (1995, p. 57), contribui com o estudo quando conclui que "[...] democratizar o lazer implica em democratizar o espaço. E se a questão for colocada em termos da vida diária, da maioria da população, não há como fugir do fato: o espaço de lazer é o espaço urbano". Diante do exposto, percebe-se que as cidades são significativas para a prática do turismo, do lazer e da cultura, devendo estar ao alcance da população os espaços abertos e/ou as áreas livres, espaços capazes de estimular a efetivação das características dos equipamentos construídos para lazer, através da movimentação de grupos, da prática de exercícios físicos gerais, da propagação de ideias nascidas da (con)vivência social ou até mesmo do hábito de contemplação do espaço urbano.

O PDESP destaca ainda, em seu Artigo 149 Parágrafo 6으, entre as diretrizes para o planejamento, a relevância do "adensamento qualificado de porções do território e, ao mesmo tempo, o aumento de áreas livres e áreas verdes, com percurso para pedestres e áreas de lazer" (PREFEITURA..., 2014). Neste contexto, pode-se notar o desafio legal a ser vencido pela administração no sentido da ampliação de espaços que garantam a participação cidadã, criando novos canais de comunicação e lazer que estimulem a construção e o fortalecimento de laços sociais. 
CENÁRIO, Brasília, V.5, n.9 | 132-139 | Dez. 2017 | p. 132 Ao citarmos a reflexão dada pelo Artigo 149, não significa que estamos apresentando-o como solução para configuração de novos espaços urbanos, nem querendo estabelecer possibilidades de acesso no que tange às necessidades da população. Segue, no entanto, a reflexão sobre que não é somente a construção de áreas livres que permite o acesso aos equipamentos de lazer, pois há barreiras socioculturais e econômicas que limitam o acesso aos equipamentos, seja por inadequações das próprias políticas públicas de lazer que orientam seu uso, seja por inversão de prioridades de gestão ou por outros motivos. A radical ampliação do nível de participação popular nas discussões e na construção, execução e fiscalização de novos espaços é necessária e deve ser proposta ao Estado. No que diz respeito às políticas públicas, é importante elencar que a análise pormenorizada da Lei 16.050 de 31 de julho de 2014 destaca a adoção de instrumentos de políticas públicas urbanas que corroboram o proposto por Lefebvre (2008) e por Marcelino (2001).

Em especial no que diz respeito às políticas dos espaços, na visão de Lefebvre (2008, p. 61), o "espaço não é um objeto científico descartado pela ideologia ou pela política; ele sempre foi político e estratégico". Para o autor, "[...] o espaço é político e ideológico, [...] porque esse espaço, que parece homogêneo, que parece dado de uma vez na sua objetividade, na sua forma pura, tal como o constatamos, é um produto social" (Lefebvre 2008, p. 62). Assim, faz-se necessário o reconhecimento do espaço por parte da população e o exercício de seu direito ao lazer, sendo considerada a preocupação com sua revitalização e conservação. A produção do espaço, segundo Lefebvre $(2008$, p. 62) se "[...] vincula a grupos particulares que se apropriam do espaço para geri-lo, para explorá-lo".

É por isso que as políticas públicas destinadas ao lazer, neste caso as definidas especificamente no PDESP, devem ser integradas como as demais ações ligadas às políticas públicas. No PDESP, esta integração se dá pelo descrito no Capítulo VIII (Desenvolvimento Social e do Sistema de Equipamentos Urbanos e Sociais), seção I, que descreve os objetivos e diretrizes do sistema de Equipamentos Urbanos e Sociais.

Em seu Artigo 303, o PDESP (PREFEITURA...,2014) define, entre outros objetivos:

II - a redução das desigualdades socioespaciais, suprindo carências de equipamentos e infraestrutura urbana nos bairros com maior vulnerabilidade social;

III - o suprimento de todas as áreas habitacionais com os equipamentos necessários à satisfação das necessidades básicas de saúde, educação, lazer, esporte, cultura e assistência social de sua população;

Já no Art. 304, o PDESP (PREFEITURA...,2014) determina que os programas, ações e investimentos, públicos e privados, no Sistema de Equipamentos Urbanos e Sociais devem

I - priorizar o uso de terrenos públicos e equipamentos ociosos ou subutilizados como forma de potencializar o uso do espaço público já constituído;

III - otimizar a ocupação dos equipamentos existentes e a integração entre equipamentos implantados na mesma quadra [...]

A questão do uso e do acesso aos equipamentos de lazer deve ser trabalhada por meio de políticas públicas, para assim tornar esses espaços efetivamente democráticos. Marcellino (2001, p. 11), apresenta preocupações quanto às políticas públicas específicas de lazer e considera que:

Falar numa política de lazer significa falar não só de uma política de atividades, que na maioria das vezes, acabam por se constituir em eventos isolados, e não em políticas de animação como processo; é preciso a política de reordenação do tempo: significa, também, falar numa política de reordenação do solo urbano, incluindo aí os espaços e equipamentos de lazer; e finalmente, numa política de formação de quadros, profissionais e voluntários para trabalharem de forma eficiente e atualizada.

Por este motivo é que se faz necessário priorizar o desenho dos princípios, diretrizes e objetivos do desenvolvimento urbano em geral, em consonância com o desenvolvimento social, mas também 
CENÁRIO, Brasília, V.5, n.9 | 133-139 | Dez. 2017 | p. 133 definir regras que orientem os processos de apropriação dos direitos e a integração de políticas públicas.

Neste sentido, no âmbito da cidade de São Paulo, a Lei de Parcelamento, Uso e Ocupação do Solo (LUOS), segunda instância normativa analisada neste texto, em seu artigo 1ำ, tem o objetivo de estabelecer normas complementares à Lei no 13.430, de 13.09.2002 - Plano Diretor Estratégico do Município de São Paulo (PDE), para instituição dos Planos Regionais Estratégicos das Subprefeituras (PRE) nos termos do disposto no inciso III do artigo 270 e do artigo 294 do PDE, dispõe sobre o parcelamento, disciplina e ordena o uso e ocupação do solo do Município de São Paulo" (PREFEITURA..., 2004).

Instituída em 2004, a LUOS complementa o antigo Plano Diretor Estratégico (de 2002), estabelecendo formas de ocupação e uso urbanístico-ambiental para cada região da cidade.

Em seu Capítulo VII, a LUOS (PREFEITURA...,2004) estabelece como objetivos da política de desenvolvimento urbano ambiental para a região centro do município:

II. fortalecer as funções turísticas de entretenimento, lazer, cultura e de negócios;

III. reforçar a diversificação de usos na área central da cidade, incentivando o uso habitacional e atividades culturais e de lazer;

IV. resgatar, valorizar e incentivar a preservação do patrimônio histórico, cultural e ambiental urbano, consolidando a identidade do centro metropolitano;

V. recuperar áreas degradadas, em especial aquelas ocupadas por habitações precárias;

VI. incentivar a multiplicidade de usos, por meio de instrumentos que permitam o aproveitamento do estoque imobiliário ocioso;

VII. estimular a alteração de uso das edificações existentes para as necessidades específicas, segundo distritos da Subprefeitura;

É interessante observar a dimensão que a seção da Política de Desenvolvimento Urbano Ambiental ganha na LUOS. Fundamental destacar, também, a importância das funções turísticas de lazer e cultura para a expansão de áreas e atividades em um determinado espaço. A valorização e a rentabilidade do solo urbano como espaço de vivência de lazer da população local e de novos usuários, na lei, destaca que a utilização do espaço não deve restringir-se à sua utilização como um objeto sem valor e que pode ser extinguir-se pelo consumo. O uso do espaço comporta a criação de novos valores de uso.

Lefebvre (2006, p. 79) nos lembra que "[...] o uso (o valor de uso, corresponde com a obra) dos lugares, dos monumentos, das diferenças, escapa às exigências da troca, do valor de troca (caracterizada como produto) ". Seguindo o pensamento do teórico, temos que o valor de troca interfere na apropriação das cidades e de seus espaços, transformando-os em lugar de consumo.

A partir do apontamento feito pelo autor, com o qual concordamos, é pertinente compreender como o espaço pode ser considerado uma realidade complexa e contraditória, pois torna-se passível de transformações pelos próprios atores responsáveis pela sua composição e apropriação, em um movimento de múltiplas reações aos problemas e contradições deste mesmo espaço.

Na menor instância que implica em interferências no uso, para lazer, do espaço público urbano de São Paulo, está o Projeto de Lei no. 439/2015, cujo objetivo é "garantir o resgate quanto à proteção da memória de luta pela recuperação da qualidade de vida dos moradores do entorno do Elevado Minhocão" (CÂMARA..., 2015). A sanção do projeto faz parte das diretrizes citadas no PDESP, que prevê o fechamento gradual do elevado como via de transporte, possibilidade de demolição ou a transformação do Minhocão em parque.

O Projeto de Lei no. 439/2015 (CÂMARA..., 2015), dá ainda "nome de Parque Minhocão ao elevado quando carro não anda lá não" e prevê, entre outras coisas, o seguinte:

Art. 1‥ A rua alta que passa na janela do quarto e da sala de muita gente, que os adultos chamam de Elevado passará a se chamar Parque Minhocão quando carros não passarem ali. 
CENÁRIO, Brasília, V.5, n.9 | 134-139 | Dez. 2017 | p. 134

$\S 1$ - Fica assegurado a todas as crianças moradoras da região o direito ao ar puro, a tranquilidade e ao espaço de lazer e cultura nos momentos em que vigorar a denominação referida no caput deste artigo;

$\S 2$ - Fica assegurado a todas as crianças o pleno direito de sonhar e lutar pelo dia em que os direitos mencionados no parágrafo anterior tornem-se permanentes e inalienáveis.

Art. 2․ - A extensão dos direitos criados nesta lei a todas as crianças do município de São Paulo dependerá exclusivamente da vontade das mesmas.

Art. 3․ - As despesas com a execução desta Lei correrão por conta das dotações orçamentárias próprias e da boa vontade dos adultos.

Art. 4ㅇ. - Esta lei entra em vigor imediatamente, revogadas todas as caretas e disposições em contrário. Às Comissões competentes.

Encontra-se ainda, na especificidade e aplicabilidade da lei que dá diretrizes para uso do espaço Parque Minhocão, medidas previstas em outros parques da cidade de São Paulo, tendo como princípio a criação de um conselho gestor e ações para garantir a participação da população. A proposta incentiva a abertura para carros somente de segunda a sexta-feira, das 21:30 até as 6:30 horas da segunda-feira, estabelecendo que aos sábados a via é fechada, a partir das 15 horas, destinando-se o seu uso para pedestres e ciclistas. Desta forma, o espaço ganha a condição de parque quando está aberto unicamente para lazer, garantindo-se direito à manutenção que os demais parques da cidade têm, como o estabelecimento da segurança pela Guarda Civil Metropolitana, iluminação, limpeza, conservação e reparos em sua estrutura física, sempre que necessário.

O espaço de representação política possui a capacidade de incorporar inúmeras reações de um indivíduo, a partir dos questionamentos que intercede e dos desejos, ideias e vontades que manifesta. Em relação ao estabelecimento de horários especiais, há que se reconhecer a decisão que deu à via outra perspectiva em relação ao uso, permitindo novas formas espontâneas de ocupação pelos usuários e a afirmação desses mesmos usuários como sujeitos de representação social.

É neste sentido que se torna importante compreender os conceitos propostos por Rita de Cássia G. Santini (1993). Para a autora, os conceitos de espaço e equipamentos frequentemente se confundem: o "espaço é entendido como o suporte para os equipamentos. E os equipamentos são compreendidos como os objetos que organizam o espaço em função de determinada atividade" (SANTINI, 1993, p. 47).

Santini (1993, p. 45) sustenta ainda que "[...] o homem não ocupa simplesmente o espaço - no sentido de dimensão e uso -, mas se sente parte integrante do ambiente onde vive, nele sabendo se orientar e atribuindo-Ihe os mais profundos significados".

Na justificativa do Projeto de Lei no. 439/2015, reconhece-se esta conexão entre a luta pela recuperação do espaço e a garantia do bem-estar das pessoas, citando-se "os efeitos da poluição sonora e ambiental da via" sobre "as crianças residentes no local" (Câmara..., 2015). Toda a ação de transformação do espaço, inclusive a recuperação e a garantia da promoção do bem-estar, dependerá de como será feita a apropriação deste espaço, pelo homem.

Santini (1993, p. 44) considera que "a utilização de parques e praças pode ser considerada como um índice positivo na qualidade de vida urbana, desde que esses espaços sejam adequados para sua compatibilização com os aspectos cruciais da vida contemporânea e, principalmente, com os lazeres".

Os processos sociais de apropriação de espaços urbanos pressupõem sempre, além da instituição dos instrumentos legais que os viabilizam, luta de classes. No caso específico da constituição do Parque Minhocão, as lutas sociais de classes são representadas por atores que intuitivamente se foram apropriando do parque, mas também pela sociedade civil organizada, última instância de interferência na forma de uso do espaço público urbano. 
CENÁRIO, Brasília, V.5, n.9 | 135- 139 | Dez. 2017 | p. 135 Como instituição, a sociedade civil organizada estabelece a conexão entre as instituições de poder público e a população, desenhando, propondo e demandando a implantação de novos instrumentos que possam orientar ações de apropriação e qualificação do espaço.

A ação política é ainda outra atribuição importante da sociedade civil organizada, no sentido de que estabelece linhas de conduta, discursos e iniciativas que combatem e contradizem críticas eventuais, por diversos organismos (poder público, imprensa, empresariado, etc.), ao processo de apropriação de espaços urbanos, pela população.

Por isso este trabalho analisa também organismos da sociedade civil que incentivam a participação popular como ponto fundamental para o reconhecimento do valor do espaço e da cultura, no Parque Minhocão. Desta forma como analise entre as associações que orientam um comportamento positivo em prol do desenho de políticas públicas voltadas para o parque, a mais atuante é a Associação Amigos do Parque Minhocão (AAPM).

A AAPM é uma organização sem fins lucrativos e apartidária que promove debates públicos e defende a transformação definitiva da via elevada em parque, visando a apropriação do espaço, especialmente pelos frequentadores da área e pelos moradores do entorno e, potencialmente, por toda população da cidade de São Paulo.

A AAPM apresenta em seu estatuto de fundação alguns dos mais relevantes princípios que defende, entre os quais a proposta de promover o trabalho coletivo, o diálogo e a sustentabilidade. A AAPM é formada por ativistas, professores, arquitetos, engenheiros, jornalistas, empresários e artistas e presidida atualmente pelo Sr. Athos Comolatti. O grupo possui sede, localizada em um apartamento que tem vista direta para o elevado.

Neste sentido, surgiu como objetivo complementar deste trabalho identificar o grau de interesse da população nessas causas defendidas pela AAPM. Para medir este interesse e o nível de engajamento das pessoas, a voz dos usuários do Parque Minhocão foi ouvida em pesquisa direta realizada por intermédio de questionários aplicados nos dias 28 e 29/05/2016, em horários alternados em manhã, tarde, noite e madrugada.

\section{Descrição da pesquisa e análise dos resultados}

O instrumento de pesquisa foi um questionário estruturado, com nove perguntas fechadas e uma pergunta aberta, tendo como foco a caracterização das atividades de lazer realizadas nas horas livres no espaço determinado e o perfil do público. Foram aplicados 100 questionários, com auxílio de dois voluntários.

Durante a investigação, foram abordados usuários em toda a extensão da via. A aplicação de cada questionário durou entre cinco e quinze minutos, dependendo da disposição do respondente e do interesse em estender $o$ assunto.

As condições de aplicação do questionário foram favoráveis devido ao clima propício e temperatura agradável para a prática de atividades físicas e lazer. 0 espaço estava bastante ocupado nos horários pré-estabelecidos para pesquisa e o movimento apresentou grande demanda no final da tarde de sábado e meio da manhã de domingo. O espaço é mais utilizado por adultos, sem predominância de gênero. Todavia, durante a tarde, registrou-se maior movimento de famílias com crianças e adolescentes.

As informações obtidas em pesquisa foram analisadas através de tabulação de dados, dividindo-se os dados nas seguintes categorias: faixa etária, renda familiar, escolaridade, distância da residência dos entrevistados ao espaço, frequência do espaço, com quem as pessoas vão ao espaço, atividades praticadas e apontamento de opiniões referentes à utilização do espaço nos finais de semana e à sua transformação em parque. Não foi seguido nenhum critério específico quanto à escolha dos entrevistados, entretanto, para melhor nível de comunicação e entendimento, priorizou-se os 
CENÁRIO, Brasília, V.5, n.9 | 136-139 | Dez. 2017 | p. 136

entrevistados com idade mínima a partir de 15 anos, sendo os usuários abordados aleatoriamente ao longo da via.

A análise de perfil de usuários considerou o fluxo de pessoas no Minhocão partindo-se do início da via, no Metrô Santa Cecília, até início da Av. Francisco Matarazzo. Constatou-se integração entre as diversas faixas etárias distribuídas ao longo do espaço e horários, sendo significativa a presença de usuários entre 15 e 29 anos. Deste modo, o Minhocão tem variáveis relacionadas às características dos usuários que usufruem do espaço, para atividades de lazer.

Quanto à escolaridade, $46 \%$ dos entrevistados têm ensino superior completo e, destes, $17 \%$ têm o ensino médio completo, seguidos de $15 \%$ com superior incompleto, $8 \%$ com fundamental completo e $7 \%$ com ensino fundamental e ensino médio incompletos, mostrando que o espaço é mais utilizado por indivíduos com mais escolaridade.

Em relação à renda mensal familiar a maioria dos entrevistados possuem renda entre 1 e 3 salários mínimos, totalizando $29 \%$ dos usuários que declaram ganhar entre $\mathrm{R} \$ \mathbf{8 8 0 , 0 0}$ e $\mathrm{R} \$ 2.640,00$, seguidos de $22 \%$ que ganham acima de $\mathrm{R} \$ 4.400,00,21 \%$ que ganham entre $\mathrm{R} \$ 2.641,00$, e $\mathrm{R} \$ 4.400,00$ e $28 \%$ dos usuários desta pesquisa não apresentaram renda diante da opção de "Não sei/Não quero opinar".

O resultado da pesquisa também apresentou a distância da residência dos usuários até o Minhocão e $48 \%$ registrou que os usuários vivem no entorno. Outros usuários próximos respondem por 18\% (de $1 \mathrm{~km}$ a $2 \mathrm{~km}$ ) dos entrevistados. Outro público significativo é de moradores que não vivem nos bairros próximos, sendo identificada a motivação de $16 \%$ usuários a percorrer distâncias maiores e superiores a $6 \mathrm{~km}$ e outros $4 \%$ dispostos a percorrer de $4 \mathrm{~km}$ a $6 \mathrm{~km}$ para usufruir do parque. Com base nesta amostra, ressalta-se a utilização, na aplicação dessa questão, de um mapa com demarcações por km, para orientar respostas objetivas pelos entrevistados.

Em relação à frequência de visita ao espaço, nota-se que $40 \%$ dos entrevistados frequenta o Minhocão todos os finais de semana, $28 \%$ de uma a três vezes ao mês, $17 \%$ mais de uma vez por final de semana e $15 \%$ apontaram que era a primeira vez. A partir das respostas dos entrevistados foi possível identificar as variações de frequências de visita ao Minhocão e descobriu-se que a maior frequência de uso desse espaço se dá em todos os finais de semana, demonstrando uma menor frequência daqueles que estão visitando a primeira vez.

$\mathrm{Na}$ análise da forma como costuma frequentar o Minhocão obteve-se que: 39\% visitam o espaço acompanhados por algum amigo, $28 \%$ em família, $18 \%$ sozinhos, $9 \%$ com companheiro e $6 \%$ com animal de estimação, considerando-se definitivamente o Minhocão um espaço promotor de sociabilidades.

Na opinião dos entrevistados, ao serem questionados sobre a abertura do Minhocão aos finais de semana para o lazer, $97 \%$ apontaram ser totalmente favoráveis e $2 \%$ parcialmente favoráveis à abertura do Minhocão aos finais de semana para o lazer. Segundo aplicação do questionário, tornase possível identificar o envolvimento das pessoas na apropriação do espaço.

Com relação à transformação do Minhocão, tem-se que 68\% dos usuários são totalmente favoráveis, seguidos de $16 \%$ parcialmente favoráveis, $10 \%$ desfavoráveis, $3 \%$ indiferentes e totalmente desfavoráveis. De forma adicional, os usuários apoiam a transformação do espaço em parque, entretanto, a falta de exploração de novos trajetos para veículos é um ponto questionado pelos entrevistados.

Sobre as atividades dos entrevistados, havia opções para atividades que poderiam ser desenvolvidas no local. Em relação à influência das variáveis relacionadas às atividades praticadas, $66 \%$ dos usuários prática caminhada. 
CENÁRIO, Brasília, V.5, n.9 | 137-139 | Dez. 2017 | p. 137 Ao exporem suas opiniões sobre se o Minhocão virasse parque traria ganho para a qualidade de vida dos moradores próximos e do entorno, $88 \%$ dos entrevistados dizem que o parque aumentaria a qualidade de vida, pois afirmam que o novo uso causa mais impactos positivas do que veículos, que provocam danos negativos.

Constatou-se influência positiva do espaço público urbano na região, proporcionando o aumento da intensidade de apropriação pelos moradores próximos, além de por outros grupos de usuários. Das motivações mencionadas pelos entrevistados que frequentam o espaço, a falta de equipamentos e espaços públicos na cidade levou os entrevistados a fazer críticas e sugestões sobre o Minhocão.

\section{Considerações}

O direito à cidade é um pressuposto social, assim como o direito ao lazer. O processo de apropriação de espaços urbanos é uma construção social que possui a capacidade de incorporar os sentimentos, ideias e forças que são apresentados pelos indivíduos no tecido social. Desta forma, para que sejam garantidos esses direitos, são necessárias políticas públicas que implementem ações capazes de criar, recuperar e manter os espaços urbanos e os equipamentos de lazer de uma cidade.

A partir da realização desta pesquisa, realizada com o objetivo de analisar os processos de apropriação de espaços públicos urbanos descritos em instrumentos legais, foi possível refletir sobre variáveis que influenciam a elaboração de políticas públicas para acesso a equipamentos de lazer e espaços públicos, destacando-se um campo de estudo em contínua evolução.

A metodologia estabelecida permitiu a compreensão da realidade analisada e do atingimento dos objetivos traçados. A partir do cruzamento de aspectos teóricos, pesquisa de campo e entrevistas com moradores e frequentadores do Minhocão, pôde-se observar, através das análises comportamentais e das respostas dos usuários, limites das políticas públicas de lazer estabelecidas em São Paulo. Pode-se perceber nos questionários a necessidade de investigações mais profundas sobre possível carência de opções de espaços públicos na cidade, para prática de atividades de lazer. Destaca-se a importância deste trabalho, sobretudo, na compreensão dos diplomas legais, das insuficientes opções de espaços e equipamentos públicos para o lazer, da falta de conservação dos que existem e da importância da reestruturação de espaços que sejam necessários à democratização do lazer.

Entende-se ainda que os dados apresentados podem ser usados como base para estudos sobre gestão compartilhada de espaços públicos e fornecer subsídios para gestores da área de turismo, no que tange a projetos relacionados ao aumento de potencial de atratividade de áreas urbanas para uso turístico. Turistas, bem como moradores e usuários, podem ter papel fundamental, como atores, nos processos sociais de produção de espaços urbanos democráticos, inclusivos, lúdicos, criativos e acolhedores. Fica evidente, neste trabalho, a relevância do lazer e do turismo para os processos de reestruturação urbana, no sentido da revisão da forma e da intensidade de uso dos espaços e dos termos de sua apropriação como lócus de experiências positivas.

Faz-se necessário e relevante conceder atenção aos espaços públicos urbanos, às demandas dos moradores do entorno desses espaços e à própria cidade, como organismo vivo. A garantia do direito à cidade e a participação efetiva da população nos processos de apropriação de espaços dá ao espaço urbano um grau de atratividade capaz de dotar os lugares de novas qualidades, capacitandoos para uso como espaços de lazer ou de turismo e para a construção de uma imagem positiva de lugar.

\section{Referências}

ASSOCIAÇÃO AMIGOS DO PARQUE MINHOCÃO. Informações sobre a associação. Disponível em: <http://minhocao.org/\#programa>. Acesso em: 28 mar. 2016. 
CENÁRIO, Brasília, V.5, n.9 | 138-139 | Dez. 2017 | p. 138

CÂMARA MUNICIPAL DE SÃO PAULO. Especial Minhocão. Disponível em:

<http://www.camara.sp.gov.br/especial-minhocao/>. Acesso em: 02 abr. 2016.

CÂMARA MUNICIPAL DE SÃO PAULO. PL 439/2015. Disponível em: < http://goo.gl/phE2h9>. Acesso em: 04 abr. 2016.

CÂMARA MUNICIPAL DE SÃO PAULO. PL 143/2016. Disponível em: < http://goo.gl/UJ74qh>. Acesso em: 31 mai. 2016.

IBGE, CENSO DEMOGRAFICO 2010. Disponível em: <http://goo.gl/vDfrzb>. Acesso em: 21 maio. 2016.

IBGE, São Paulo - SP. Disponível em: <http://goo.gl/eMroHh>. Acesso em: 21 maio. 2016.

LEFEBVRE, Henri. Espaço e política. Belo Horizonte: UFMG, 2008(1972).

O direito à cidade. 4 ed. São Paulo: Centauro, 2004(1968).

MARCELLINO, Nelson Carvalho. Estudos do lazer: uma introdução. 3. ed. Campinas, SP: Autores Associados, 2002. (Coleção educação física e esportes).

Fazer Lazer). Lazer e humanização. 2 ed. Campinas, SP: Papirus, 1995. (Coleção

Lazer \& esporte: políticas públicas. 2. ed. Campinas, SP: Autores

Associados, 2001. (Coleção educação física e esportes).

PREFEITURA MUNICIPAL DE SÃO PAULO. Lei no 16.050, de 31 de julho de 2014. Aprova a Política de Desenvolvimento Urbano e o Plano Diretor Estratégico do Município de São Paulo e revoga a Lei no 13.430/2002. Disponível em: <

http://www.prefeitura.sp.gov.br/cidade/secretarias/upload/chamadas/2014-07-31 - lei 16050 plano diretor estratgico 1428507821.pdf>. Acesso em: 13 mar. 2016.

PREFEITURA MUNICIPAL DE SÃO PAULO. Lei no 13.885, de 25 de agosto de 2004. Lei de Parcelamento, Uso e Ocupação do Solo (LUOS). Disponível em: <

http://www.prefeitura.sp.gov.br/cidade/secretarias/upload/desenvolvimento urbano/arquivos/plan o diretor/lei de zoneamento.doc>. Acesso em: 02 abr. 2016.

PREFEITURA MUNICIPAL DE SÃO PAULO. Os prefeitos de São Paulo. Disponível em: $<$ http://goo.gl/kxE7pY>. Acesso em: 21 mai.2016.

RADAR MUNICIPAL. Projeto de Lei no 439/2015. Disponível em: <http://goo.gl/FeCDF1>. Acesso em: 04 abr. 2016.

RADAR MUNICIPAL. Projeto de Lei no 143/2016. Disponível em: <http://goo.gl/hJpsyL>. Acesso em: 31 mai. 2016.

SANTINI, R. de C. G. Dimensões do lazer e da recreação. São Paulo: Editora Angelotti, 1993.

VALOR ECONÔMICO. São Paulo: Haddad sancionará projeto de lei que dá status de parque ao Minhocão. Disponível em: <http://goo.gl/sBoKZ6>. Acesso em: 15 mar.2016. 
CENÁRIO, Brasilia, V.5, n.9 | 139-139 | Dez. 2017 | p. 139 VEJA SÃO PAULO. Associação é criada para transformar Minhocão em parque. Disponível em: <http://goo.gl/bBtr43>. Acesso em: 30 mar.2016. 